\title{
Strategies for the Implementation of Service Innovations
}

Cornell Hospitality Quarterly 53(3) 187-195

(C) The Author(s) 2012

Reprints and permission:

sagepub.com/journalsPermissions.nav DOI: | 0.1 | 77// 9389655 |2448| 76 http://cqx.sagepub.com

@SAGE

\author{
Cathy A. Enz'
}

\begin{abstract}
Implementation strategies are the ways in which information about a new service innovation are shared with those employees who must execute on the innovation. This article examines the relationship between innovation success and the frequency of use of various strategies for the implementation of two specific nationwide service innovations in the North American hotels of a global lodging chain. Cost and service quality-based innovations were found to rely on different implementation strategies, suggesting that the connection between an implementation strategy and success depends on the type of innovation. In the hotel chain studied, the most successful strategy for implementing quality innovations was individual counseling, while rewards and focus groups were most strongly associated with success when implementing costbased innovations. A mix of execution strategies including implementation by persuasion, leader intervention, participation, and even edict were linked to service innovation success. Participative employee-centered implementation strategies emerged as the most critical in the diffusion of service innovations.
\end{abstract}

\section{Keywords}

Change management, innovation, strategy, hotel management, service quality

During difficult economic periods, innovation is touted as a source of value creation in part because firms that implement innovations countercyclically are often more prepared to rebound when times get better (Beinhocker, Davis, and Mendonca 2009; Schumpeter 1934). However, implementing innovations is not easy in good times or bad. While a sizable literature has focused on product innovation, only recently has attention been given to service innovation (Vila, Enz, and Costa 2012; Enz 2011; Verma et al. 2008). Service innovation is defined as the introduction of novel ideas that focus on services that provide new ways of delivering a benefit, new service concepts, or new service business models through continuous operational improvement, technology, investment in employee performance, or management of the customer experience (Verma et al. 2008).

The nature of services may explain the limited research that has explored innovation and its implementation. Labor intensity, high variability of delivery, coproduction with the consumer, intangibility, and the perishability or time sensitivity of services makes innovation in services substantially different in type and in adoption processes from the innovations in traditional manufacturing settings (Fitzsimmons and Fitzsimmons, 2004; Johnston and Clark, 2008). Service innovation is deeply rooted in reconfiguring the value creation process, involving the development of new skills, attitudes, and competencies to cocreate and deliver value to customers (Vargo and Lusch 2004). Given that focus on customers, and the critical role of the social system in the implementation of change, it is likely that the success of implementing service innovations relies on appropriate processes and administrative structures. This suggests that investments in finding ways to get employees to adopt an innovation may be critical to success. The transition period between a decision to adopt a service innovation and its regular use is called the postadoption implementation stage (Dewett, Whittier, and Williams 2007). I'm focusing on this stage of service innovation because it clearly is critical to success. This study examines the frequency of use of different implementation strategies in different types of service innovations, and the relationship between the type of strategy used and the success of the innovation.

Service innovation rests on both creating something new, and on coproducing it. One clear feature of service innovation is that it is characterized as having a greater organizational dimension than innovations in manufacturing contexts (Weissenberger-Eibl and Koch 2007). Indeed some researchers have argued that a firm's long-term success may rely more on an overall firm-level innovation

'Cornell University School of Hotel Administration, Ithaca, NY, USA

Corresponding Author:

Cathy A. Enz, Cornell University School of Hotel Administration, Ithaca, NY I4853

Email: cae4@cornell.edu 
orientation that produces the capabilities that spawn innovations and less on specific innovations (Siguaw, Simpson, and Enz 2006). Such an organizational innovation system or orientation may be particularly critical for the successful execution of service innovations.

A strong climate for the implementation of service innovations that takes into account how the innovation fits the company's value proposition and stresses employee motivation has also been given some conceptual and empirical attention (Klein and Sorra 1996; Cadwallader et al. 2010). In a case study of two Walt Disney World hotels, the authors present a framework for implementing change. To ensure success, they argue for the inclusion of employees who are affected by the change, and using direction, participation, and consultation strategies (Ford, Heisler, and McCreary 2008). Overall, that study suggests that within hospitality organizations innovation is social and embedded in a cultural context. Thus, implementing service innovations successfully may be driven by more participative and group-based strategies that ensure employees have the right attitudes, skills, and competencies to deliver on the new service concept, benefit, or operational improvement.

\section{Implementing Innovations Postadoption}

Everett Rogers's (1995) classic work on the diffusion of innovation serves as the theoretical foundation for understanding both preadoption processes to generate and foster innovation and postadoption implementation within a firm. Preadoption processes and other antecedents of innovation have been explored extensively in the hospitality and tourism literature (Vila, Enz, and Costa 2012; Aldebert, Dang, and Longhi 2011; Andreu et al. 2010; Anne-Mette 2010). Larger hotels with higher levels of experience, for example, have been found to be more innovative (Jacob and Groizard 2007), while ambiguity, inconsistent support, and a lack of urgency have been found to hinder adoption of innovations (Chan 2011).

Once an innovation has been selected, postadoption processes constitute the internal diffusion strategies directed toward members of a social system (Rogers 1995). As I mentioned, the role of postadoption implementation has received relatively little empirical attention (Dewett, Whittier, and Williams 2007; Cadwallader et al. 2010). Postadoption implementation approaches involve the ways in which information about the new idea are shared with those employees who must execute on the innovation. Even though this execution stage is most often identified with innovation failure, it receives the least attention from innovation researchers (Pellissier 2011; Dewett, Whittier, and Williams 2007; Kotter 2002; Klein and Sorra 1996). Efforts to examine postadoption implementation have primarily involved conceptual models to guide future study or qualitative case studies with limited generalizability. Nevertheless, many researchers acknowledge the lack of studies in this area and the importance of understanding this important transition period.

Cadwallader et al. (2010) argue that the translation of service innovations into results is highly dependent on the actions of frontline employees, while Dewett, Whittier, and Williams (2007) contend that managers can most influence human factors in the implementation process. In a study of hotels and restaurants in China, researchers found that training customer-contact employees to possess multiple skills was significantly related to both incremental and radical innovation (Chang, Gong, and Shum 2011). Indeed, unlike the traditional goods-dominant logic paradigm with its roots in technological product inventions, in a servicedominant logic paradigm, "goods are best viewed as distribution mechanisms for service provision" (Vargo and Lusch 2004, 9). This perspective would suggest that the postadoption implementation process may actually be a key component of the innovation itself in service firms. In other words, execution may be the innovation in service contexts, as much as the new idea itself, since employees are expected to use the innovation directly in relationships with customers or support the innovation's use. Given that the innovation implementation literature has virtually ignored research on postadoption diffusion and specifically the strategies used to ensure that employees utilize innovations, this study seeks to address this gap in the literature.

In the implementation process, the nature of the informationexchange relationship determines the conditions under which an employee receives knowledge or has experience using the new idea. Several different information-exchange strategies can be used, including those focused on individuals, typically, individual counseling by managers or change agents, and those at the group level, such as staff meetings, cross-functional teams, and focus groups. Other strategies for implementing innovations noted in the literature include creating a crisis to enlist support and critical analysis of problems with current approaches (Kotter 1996). Trainers, idea champions, a point person (leader or facilitator), or even directives from senior management are other strategies of implementation driven through power relationships and leadership. Daft and Becker (1978) suggest that incentives and rewards are also factors that enable implementation success.

This study explores a wide range of employee-based, group, and leader-driven implementation strategies used in the introduction of two distinct types of service innovation. Because a service innovation is composed of a variety of different activities that seek to change what exists into something better (Rogers 1995), it is necessary to employ an array of different implementation strategies. The questions of interest in this study are "Which implementation strategies are most frequently deployed?" and "What is the relationship between a given implementation approach and overall success of systemwide innovations?" Before we 
examine implementation strategies, I offer an integrative framework to help organize the diverse strategies.

\section{Categorizing Implementation Strategies}

One of the few conceptualizations of implementation strategies was offered by Nutt (1986), who assessed 91 case studies of planned change in hospitals and identified the following four categories of implementation strategies: intervention, participation, persuasion, and edict. Because this study uses Nutt's taxonomy, let us look at his explanation of each category.

\section{Intervention}

Intervention comprises strategies in which the leader benchmarks other organizations and attempts to justify a change in performance by highlighting performance inadequacies and monitoring performance. Creating a crisis and collecting information to help create dissatisfaction are strategies within this category.

\section{Participation}

Participation includes delegation strategies that help to empower and engage employees in the change process. Task forces, cross-functional teams, focus groups, and employee surveys are examples of ways to tap employee views and elicit commitment and involvement in the execution process.

\section{Persuasion}

Persuasion captures the activities of internal and external experts who use a variety of approaches to sell ideas to employees. Internal public relations efforts, along with networking and trainers, are often used to persuade employees that the innovation has benefits for them and the firm.

\section{Edict}

An edict may come as a command from a senior-ranking executive or it may involve a designated champion who attempts to drive the change through formal or even personal power. Edict often involves directives calling for immediate adoption of a practice.

In addition to adapting the conceptual framework devised by Nutt (1986) from the hospital context to hospitality, this study also employs a quantitative measurement approach. I also incorporate Rogers's (1995) notion of diffusion, which emphasizes the ways in which an innovation is communicated to employees and other internal players. This will permit an examination of various diffusion strategies, such as individual counseling and internal workshops.
Finally, this study draws a distinction between individual, group, and leader-driven implementation strategies. Based on the conceptual framework of Nutt (1986), the following hypothesis is offered.

Hypothesis 1: A variety of implementation strategies including implementation by participation, intervention, persuasion, and edict strategies will be used in the introduction of service innovations.

\section{Innovation Success}

The innovation literature to date has focused primarily on the antecedents to innovation or the degree of innovation. The linkages found in the literature involve those between industry innovation and productivity growth for countries (see Griffith et al. 2006 as an example of this type of research), and the linkage between innovation assets and firm performance (Fang, Palmatier, and Grewal 2011). Fang, Palmatier, and Grewal (2011) explored how the configuration of customer and innovation assets influences performance and operationalized innovation asset breadth by the number of patents a firm possesses.

Missing from these studies is an examination of the process of introducing innovation into the firm. Moreover, the success of innovation has been measured by a handful of specific, readily calculated approaches (Simpson, Siguaw, and Enz 2006). Those include the number of innovations adopted (Han and Srivastava 1998), number of patents (Fang, Palmatier, and Grewal 2011), new product introduction, R\&D expenditures, order of market entry (e.g., Manu and Sriram 1996), and stock market value (e.g., Sharma and Lacey 2004). Simpson, Siguaw, and Enz (2006) found in their study of outcomes that market advantages, operational excellence, and employee satisfaction were also critical positive outcomes, while rising costs and the lack of employee skills were negative outcomes of innovation. The framework of outcomes developed by Simpson, Siguaw, and Enz (2006) informed the approach to operationalizing innovation success in this study because of its attention to producing positive outcomes from innovation within service contexts. Hotel productivity, increased profitability, cost reduction, efficiency, and employee advantages are key elements of this study's approach to innovation success. A recent study of innovation in Spanish hotels revealed that senior-level research and development managers in large hotel chains also reported relying on increasing gross operating profit and sales revenue to measure the effectiveness or profitability of innovations (Vila, Enz, and Costa 2012).

If diffusion is an integral component of the innovation, as I have posited, then understanding how a firm uses different implementation strategies is essential. Since service innovation is a complex process in which both inputs and outputs to providing services are highly variable, a configuration 
of different implementation strategies may be necessary to achieve the successful introduction of a new process, system, or idea. Thus, I hypothesize that a variety of different implementation strategies should be related to organizational performance, as follows.

Hypothesis 2: A variety of implementation strategies, including participation, intervention, persuasion, and edict, will be related to innovation success.

Service innovations involve considerable human activity in which both employees and customers are engaged simultaneously in the delivery process (Bate and Robert, 2006; Chase, 1978; Verma et al. 2008). As such, we would expect that participation-focused implementation strategies such as individual counseling, focus groups, employee involvement, task forces, and employee surveys would be critical to achieving successful implementation. However, not all service innovations are driven by customer-facing employees. Different types of innovations may diffuse differently. Hence, the implementation strategies that are most successful may vary depending on whether a cost- or a quality-based service innovation is deployed (Damanpour 1987). In some cases service innovations are customer facing and focused on customers' needs and service delivery. In other cases, service innovations may focus on back-of-the-house cost-control systems and organizational design. I expect that the implementation strategies that work successfully for one type of innovation may not be viable for another type, even within the same hospitality firm or location. This perspective is consistent with configuration theory (Siggelkow 2002), in the sense that a portfolio of implementation strategies is necessary to effectively introduce a given innovation, and the configuration of strategies will differ by type of innovation.

While research has not addressed the extent to which the type of innovation influences implementation strategy selection, some have argued that administrative innovations may diffuse differently than technological innovations (Dewett, Whittier, and Williams 2007). Others suggest different diffusion processes for product versus process innovations, and for radical versus incremental innovations (Damanpour 1991; Enz and Harrison, 2008; Enz, 2010)). Hence, the following hypothesis is offered.

Hypothesis 3: The configuration of implementation strategies linked to innovation success will differ for cost- versus quality-based service innovations.

Given that the implementation process in services is messy and the role of employees in creating new service products and experiences is critical, one would expect that employee-focused implementation strategies will be extremely important, but I include a wide array of other strategies grounded in the literature on innovation diffusion and change (Rogers 1995; Kotter 1996; Nutt 1986) to reflect the complexity embedded in innovation. Consequently, this study focuses on two systemwide innovation initiatives and twenty-six implementation strategies. I examine whether the two service innovations rely on different implementation strategies.

\section{Methodology Sample}

The data for this study were gathered from within a global hotel chain. Hotel-level innovation implementation practices were gathered via surveys from the general manager of each hotel. A questionnaire was sent to all North American GMs via internal company mail with the endorsement of the company's president. Fifty-three GMs returned completed questionnaires, constituting a response rate of 93 percent. The typical respondent was a forty-four-yearold male ( $87 \%$ males in total sample) who has been with the parent company for sixteen years and has been a general manager for nine years. Seventy-nine percent of the respondents were college educated, and the mean tenure in their current hotel was two and one-half years.

\section{The Innovations}

Two systemwide innovations were introduced in the hotel chain prior to the survey. One innovation was service quality based. This initiative focused on monitoring customer needs and enhancing service quality during guest contact experiences by tracking customer satisfaction, conducting service inspections, and making continuous improvement initiatives. The second innovation focused on cost controls, while still providing high value to the customer. Innovations in this initiative included changing the organizational design of work groups, staggered scheduling, reducing managers, and expanding employee responsibilities.

Individual hotels were free to adopt these service innovations or not (and, indeed, three properties implemented neither one, but chose different initiatives). For those that implemented one of the two chainwide innovations, respondents were asked to select the practice that had been most successful and effective for their hotel over the previous eighteen months. About half of the hotels chose the costbased innovation as the winner, and the other half picked the quality initiative as their successful program.

\section{Measured Variables}

After the GMs wrote a description of their innovation, I presented the list of twenty-six implementation strategies derived from the literature on the diffusion of innovation and change (Rogers 1995; Kotter 1996) and on Nutt's (1986) conceptual framework. Using a five-point Likerttype scale (ranging from never to very often), the survey 


\section{Exhibit 1:}

\section{Implementation Strategies}

Implementation by Intervention

Benchmarking: looked at other organizations (in and out of hospitality) for best practice examples

Creation of crisis: the situation was portrayed as a crisis in order to enlist support for the implementation of the practice Internal workshops: information sessions were conducted by managers

Staff meetings: discussions at regular staff meetings

Memos: brief reports and details were circulated explaining the practice

Collecting information: information was gathered to help understand the current situation and the use of this practice

Customer feedback: guests were surveyed regarding their satisfaction, needs, wants, and expectations of service and product quality

Eliminate old behaviors (Making room): showed why some old behaviors are no longer appropriate and asked to cast aside the old

ways to make room for the new practice

Implementation by Participation

Employee involvement: employees were asked for their ideas and impressions regarding the need for this practice

Task force: a group was formed to officially research and plan implementation

Cross-functional teams: across-department teams met to discuss the practice

Employee surveys: employees were surveyed regarding their attitudes and opinions of their job and work environment

Focus groups: groups composed of managers and line employees gathered to brainstorm ideas regarding how to institute the practice/activity

Departmental self-start: one or more managers in a department decided on their own to implement; their success led to adoption in other areas

Individual counseling: met with individuals to answer questions or dispel fears regarding the new practice

Volunteer soft-start: volunteers from among management and staff were given the opportunity to achieve small successes in working with the practice on their own

Implementation by Persuasion

Outside expert: outside consultant introduced the practice

Rewards: one or more managers or departments pledged their support for the practice in exchange for some future benefit

Trial or experiment: a small test of the practice was conducted in a specific area

Internal public relations: various internal media (newsletters etc.) Were used to disseminate information that caused people to view implementation favorably

Trainers: individuals who had expertise in the use of this practice trained employees or managers

Networking: supporters discussed the practice informally

Implementation by Edict

Directive: general manager or corporate personnel issued a directive calling for immediate adoption of the practice

Idea champions: designated individuals were assigned responsibility for implementation

Review process: top management regularly reviewed the practice

Point person: a leader/facilitator was designated

asked respondents to indicate the degree to which each strategy was used to implement their successful innovation. The survey briefly described each approach to ensure the GMs understood each implementation strategy (see Exhibit 1).

Following the framework devised by Simpson, Siguaw, and Enz (2006), respondents were asked to assess the success of the innovation in improving productivity, reducing costs, improving decision making, increasing efficiency, improving employee skills, enhancing employee job satisfaction, and increasing profitability. Each of these elements of success was measured using a five-point Likert-type scale measuring success on a scale of not at all successful to completely successful. These seven success factor ratings were combined to produce a composite measure of success. A principal components factor analysis of the seven-item success measure revealed a single-factor structure with an eigenvalue of 3.98. Factor loadings ranged from .70 to .84, and total variance explained was 57 percent. I should note that in self-report surveys such as this one, common method variance is often raised as a concern. Recent work suggests that while common method bias is likely to exist in studies of the type done here, the magnitude of effect is likely to be small (Meade, Watson, and Kroustalis 2007).

\section{Findings}

Means, standard deviations, and Pearson product-moment correlations with the success measure were calculated for each of the twenty-six implementation strategies, as shown in Exhibit 2. The findings support the first hypothesis that a wide variety of implementation strategies are used in the introduction of service innovations. The most frequently used implementation approaches were, in order of frequency, (1) regular staff meetings in which the innovation was discussed (Intervention-group), (2) idea champions who were 


\section{Exhibit 2:}

\section{Implementation Strategies}

\begin{tabular}{|c|c|c|c|}
\hline Implementation Strategy & Mean Usage & Standard Deviation & Pearson Correlation with Success \\
\hline Individual counseling & 3.69 & 1.039 & $.434 * *$ \\
\hline Rewards & 2.59 & 1.344 & $.366 * *$ \\
\hline Benchmarking & 3.13 & 1.205 & $.363^{* *}$ \\
\hline Focus groups & 3.33 & 1.366 & $.344^{*}$ \\
\hline Employee involvement & 3.71 & 1.226 & $.333^{*}$ \\
\hline Review process & 3.77 & 1.022 & $.291 *$ \\
\hline Trial or experiment & 2.96 & 1.283 & $.291 *$ \\
\hline Point person & 3.88 & 1.182 & $.290 *$ \\
\hline Eliminate old behavior & 3.49 & 1.138 & .251 \\
\hline Cross-functional teams & 3.50 & 1.146 & .235 \\
\hline Volunteer soft-start & 3.12 & 1.211 & .215 \\
\hline Staff meetings & 4.10 & 0.799 & .179 \\
\hline Networking & 3.80 & 0.917 & .157 \\
\hline Directive & 3.08 & 1.370 & .137 \\
\hline Memos & 3.35 & 1.036 & .137 \\
\hline Internal public relations & 3.02 & 1.129 & .124 \\
\hline Employee surveys & 3.00 & 1.296 & .114 \\
\hline Departmental self-start & 2.88 & 1.231 & .114 \\
\hline Trainers & 3.31 & 1.336 & .164 \\
\hline Creation of a crisis & 1.88 & 0.973 & .140 \\
\hline Idea champions & 3.90 & 1.118 & .092 \\
\hline Internal workshops & 3.39 & 1.002 & .065 \\
\hline Task force & 3.12 & 1.465 & .051 \\
\hline Collecting information & 3.75 & 1.163 & -.046 \\
\hline Outside expert & 2.27 & 1.282 & -.010 \\
\hline Customer feedback & 3.35 & 1.293 & -.100 \\
\hline
\end{tabular}

$* p \leq 0.05 ; * p \leq .01$.

individuals assigned responsibility for implementation (Edict-leader), (3) point persons who were designated leaders or facilitators of the innovation (Edict-leader), (4) networking through informal discussions (Persuasion-group), (5) a review process in which senior management reviewed the innovation (Edict-leader), (6) employee involvement in which employees were asked for their ideas (Participationindividual), and (7) individual counseling in which one-onone conversations were held to answer questions and dispel fears (Participation-individual). Implementation approaches with the greatest degree of variation in their use across hotels were (1) task forces (Participation-group), (2) a directive from the GM (Edict-leader), (3) focus groups of managers and employees who brainstormed ideas for how to implement the innovation (Participation-group), (4) future rewards for employees in exchange for supporting the innovation (Persuasion-group and individual), and (5) the use of trainers who had expertise in the use of the innovation (Persuasion-leader). In sum, staff meetings were almost universal - both the most frequently used tactic and the one with the least amount of variation in use.

\section{Most Important Strategies}

The results provide support for hypothesis 2, revealing a wide variety of implementation strategies related to innovation success. Meeting one-on-one with individuals via individual counseling (Participation-individual) was the strategy most strongly correlated with the GMs' perceptions of innovation success (see Exhibit 2). Other strategies significantly associated with success included the use of rewards (Persuasion-individual/group), benchmarking other organizations (Intervention-leader), focus groups (Participation-group), employee involvement (Participationindividual), senior management review process (Edictleader), trial or experiment using small tests of the innovation (Persuasion-group), and use of a designated point person (Edict-leader).

Some popular techniques did not seem to result in success. The use of idea champions, which was found to be valuable in studies of traditional product development (Zirger and Maidique 1990), was not strongly linked to success by the responding GMs, even though this edict strategy 


\begin{tabular}{|c|c|c|}
\hline $\begin{array}{l}\text { Implementation } \\
\text { Strategy }\end{array}$ & $\begin{array}{l}\text { Success of } \\
\text { Cost-Based } \\
\text { Innovation }\end{array}$ & $\begin{array}{c}\text { Success of } \\
\text { Quality-Based } \\
\text { Innovation }\end{array}$ \\
\hline Cross-functional teams & .21 & .24 \\
\hline Internal workshops & -.13 & .10 \\
\hline Staff meetings & -.18 & .36 \\
\hline Outside expert & .08 & -.18 \\
\hline Task force & .35 & -.16 \\
\hline Networking & .22 & .11 \\
\hline Directive & -.11 & .26 \\
\hline Memos & -.22 & .34 \\
\hline Idea champions & $.40 *$ & -.02 \\
\hline Internal public relations & .26 & .02 \\
\hline Collecting information & -.02 & .001 \\
\hline Employee surveys & -.08 & .35 \\
\hline Customer feedback & -.21 & .05 \\
\hline Departmental self-start & .29 & .03 \\
\hline Review process & .20 & .34 \\
\hline Trial or experiment & .36 & .28 \\
\hline Trainers & .20 & .14 \\
\hline Employee involvement & .39 & .33 \\
\hline Point person & .23 & $.53^{*}$ \\
\hline Benchmarking & .26 & $.46 *$ \\
\hline Individual counseling & -.14 & $.67^{* *}$ \\
\hline Rewards & $.57 *$ & .23 \\
\hline Volunteer soft start & $.40 *$ & -.006 \\
\hline Creating crisis & .12 & .08 \\
\hline Eliminate old behavior & -.16 & $.50 *$ \\
\hline Focus groups & $.48 *$ & .30 \\
\hline
\end{tabular}

$*_{p} \leq 0.05 ; * * p \leq 0.01$.

was used extensively. Moreover, the almost universal staff meetings (Intervention-group) and informal networking (Persuasion-group) were also not associated with innovation success. On the other hand, a little-used approach, the persuasion strategy of using rewards in exchange for employee support, was positively and significantly correlated with innovation success.

\section{Strategies for Success in Hotel Systemwide Innovations}

Exhibit 3 shows the correlations between each implementation strategy and the measure of innovation success separately for the two systemwide innovations. Hypothesis 3 argues that the cost-based and the quality-based innovations may diffuse differently, meaning that different implementation strategies would be viewed as successful according to the type of innovation.

Indeed this was the case. The results show that the correlation between implementation strategies and success does differ by innovation type in keeping with the third hypothesis. The following implementation strategies were significantly correlated with the success of the cost-based innovation: employee rewards (Persuasion-individual/ group), focus groups who brainstormed implementation (Participation-groups), idea champions who led the initiative (Edict-leader), and a soft start in which volunteers were given an opportunity to achieve small successes in working on their own (Participation-group). For the quality innovation, the successful strategies were individual counseling (Participation-individual), use of a point person to facilitate implementation (Edict-leader), and eliminating old behaviors to make room for the new innovation (Intervention-leader). As you see, the two sets of significant correlates with success have no strategies in common.

Certain strategies appeared to impede the success of either the cost-based innovation or the quality-based initiative, although none were statistically significant. For the cost-based concept, the strategies that were negatively correlated with success were customer feedback, memos, staff meetings, eliminating old behavior, and individual counseling. Strategies with negative correlations for the qualitybased innovation were use of an outside expert, task forces, idea champions, and a volunteer soft start. Again there was no overlap in the two sets of strategies that showed a negative correlation with success.

\section{Discussion and Conclusions}

Overall, the use of participative strategies were the most strongly correlated with innovation success. At the top of the list was the individual-focused strategy of counseling, although employee involvement and focus groups were also strongly correlated with innovation success. This finding is consistent with the literature that has suggested that participation helps to promote innovation adoption (Pellissier 2011). Even though intervention and edict strategies presented a mixed picture of success, they were the most frequently used, which suggests that leaders tended to be protagonists who devised a rationale for action and used their power to control implementation and obtain compliance. For example, staff meetings and idea champions were intervention and edict strategies that were most often used but not positively related to innovation success. Although the literature would suggest that reliance on centralized and formal authority might hamper implementation (Cohn and Turyn 1980), this study found, to the contrary, that some intervention (i.e., benchmarking) and edict (i.e., review processes) strategies were successful in the implementation process. The results would indicate that innovation success was strongly and significantly correlated to the use of a combination of participation, persuasion, intervention, and edict strategies. So while participation was most often linked to success, selected strategies from all four implementation categories were important. 
Most critically, the results also reveal that the nature of the specific service innovation dictates the appropriateness of a given implementation strategy. A quality-based innovation was more successful when leader-driven intervention and edict strategies were deployed, for example, combined with the highly interpersonal participation strategy of one-on-one counseling. At the same time, it is interesting to note that this participative strategy was negatively and insignificantly related to success in the implementation of a cost-based innovation. Because the quality innovation is customer-facing, individual counseling becomes a high priority to ensure that exchanges with customers are adopted by individuals who are motivated to deliver on the quality expectations. In addition, the intervention strategies were used to justify the consistent delivery of new norms in the service encounter by focusing on eliminating old behaviors and benchmarking best practices. Leaders played the role of facilitation and ensuring consistent delivery of new services. Thus, the quality innovation involving customer contact appears to require leader facilitation. This allows the leader to address staff skill issues, create a focus on not doing things the old way, and promoting best practices of other organizations.

In contrast, the cost-focused service innovation was more successful when group participation strategies were used, along with group based persuasion. If such an innovation involves radical change in processes it would require participative group strategies, and if it is disruptive to the organization it would necessitate attention to persuasive techniques such as incentives and rewards. The company's cost-based innovation required employees to assume different roles and responsibilities and put additional pressure on them to manage scarce resources. Frequent use of incentives or monetary rewards for adoption was linked to success in the cost-based innovation, but not the quality-based innovation. Consistent with the arguments of Damanpour (1987) this study highlights the fact that a one-size-fits-all approach to implementing service innovations is undesirable. Future research should examine the best implementation strategies for a broader array of service innovations.

Note that although staff meetings, memos, and workshops are intended as information-sharing strategies, they provide little attention to individual questions and concerns. Because of their social settings, these approaches may be easy to use, although they are not positively linked to innovation success. Other commonly used participation strategies, such as task forces or cross-functional teams, also did not appear linked to success. This finding suggests that the complex social system of hotels and the climate in which implementation is embedded may either facilitate or impede the use of particular participation strategies often touted in the adoption of innovations. Examining the complex linkages between a social system's structure and implementation is a fruitful area for future research and an understudied domain within the diffusion of innovation literature.
These findings should encourage hospitality managers to think about which implementation approaches should be used in future innovation efforts. The study findings raise some doubt as to the effectiveness of such popular techniques as meetings and memos for the diffusion of new ideas. A deployment of a combination of participative, persuasive, intervention, and edict-based strategies seems to ensure the best balanced approach to implementation. Given that service innovations are deeply rooted in reconfiguring the value creation process, it is not surprising that individual employee counseling and rewards for pledging support are correlated with success. Counseling helps employees to develop the new skills, attitudes, and competencies they need to cocreate and deliver value to customers. Rewards speed the process by motivating adoption (Cadwallader et al. 2010). Since employees are called on both to create something new and to coproduce it with customers when a company engages in service innovations, it is important to use strategies for future implementation efforts that place leaders in the role of facilitator rather than offering a directive for immediate action. This study has provided preliminary results to suggest that both individual and group participative and hence employee-centric strategies present the best chance a hotel company may have for successfully introducing service innovations.

\section{Author's Note}

This article is based on a presentation at QUIS 12, the International Research Symposium on Service Excellence Management.

\section{Declaration of Conflicting Interests}

The author(s) declared no potential conflicts of interest with respect to the research, authorship, and/or publication of this article.

\section{Funding}

The author(s) received no financial support for the research, authorship, and/or publication of this article.

\section{References}

Aldebert, B., R. Dang, and C. Longhi. 2011. Innovation in the tourism industry: The case of tourism@.Tourism Management 32 (5): 1204-17.

Andreu, L., J. Aldas, J. Bigne, and A. Mattila. 2010. An analysis of e-business adoption and its impact on relational quality in travel agency-supplier relationships. Tourism Management 31 (6): 777-87.

Anne-Mette, H. 2010. A review of innovation research in tourism. Tourism Management 31 (1): 1-12.

Bate, S. P., and G. Robert. 2006. Experience-based design: From redesigning the system around the patient to co-designing services with the patient. Quality \& Safety in Health Care 15 (5): 307-10.

Beinhocker, E., I. Davis, and L. Mendonca. 2009. The ten trends you have to watch. Harvard Business Review, July-August, 55-60. 
Cadwallader, S., C. B. Jarvis, M. J. Bitner, and A. L. Ostrom. 2010. Frontline employee motivation to participate in service innovation implementation. Journal of the Academy of Marketing Science 38:219-39.

Chan, E. 2011. Implementing environmental management systems in small- and medium-sized hotels: Obstacles. Journal of Hospitality \& Tourism Research 35 (1): 3-26.

Chang, S., Y. Gong, and C. Shum. 2011. Promoting innovation in hospitality companies through human resource management practices. International Journal of Hospitality Management 30 (4): 812-30.

Chase, R. B. 1978. Where does the customer fit in a service operation? Harvard Business Review, November-December, 137-45.

Cohn, S. F., and R. M. Turyn. 1980. The structure of the firm and the adoption of process innovations. IEEE Transactions on Engineering Management 27: 98-102.

Daft, R., and S. W. Becker. 1978. Innovation in organizations. New York: Elsevier.

Damanpour, F. 1991. Organizational innovation a meta-analysis of effects of determinants and moderators. Academy of Management Journal 34:555-90.

Damanpour, F. 1987. The Adoption of Technilogical, Administrative, and Ancillary Innovations: Impact of Organizational Factors. Journal of Management, 13 (4): 675-688.

Dewett, T., N. C. Whittier, and S. D. Williams. 2007. Internal diffusion: the conceptualizing innovation implementation. Competitiveness Review 17 (1): 8-25.

Enz, C. 2010. Hospitality strategic management: Concepts and cases. 2nd edition. New York: John Wiley.

Enz, C. 2011. Improving the guest experience through service innovation: Ideas and principles for the hospitality industry. Cornell Hospitality Roundtable Proceedings 3 (7), June.

Enz, C., and J. Harrison. 2008. Innovation and entrepreneurship in the hospitality industry. In The handbook of hospitality management, edited by Roy Wood and B. Brothers. London: Sage.

Fang, E., R. Palmatier, and R. Grewal. 2011. Effects of customer and innovation asset configuration strategies on firm performance. Journal of Marketing Research 48 (3): 587-602.

Fitzsimmons, J. A., and M. J. Fitzsimmons. 2004. Service management. 4th edition. Boston, MA: Irwin.

Ford, R., W. Heisler, and W. McCreary. 2008. Leading change with the 5-P model. Cornell Hospitality Quarterly 49 (2): 191-205.

Griffith, R., E. Huergo, J. Mairesse, and B. Peters. 2006. Innovation and productivity across four European countries. Oxford Review of Economic Policy 22 (4): 483-98.

Han, J., and R. K. Srivastava. 1998. Market orientation and organizational performance: Is innovation a missing link? Journal of Marketing 62:30-45.

Jacob, M., and J. Groizard. 2007. Technology transfer and multinationals: The case of Balearic hotel chains' investments in two developing economies. Tourism Management 28 (4): 976-92.

Johnston, R., and G. Clark. 2008. Service operations management. 3rd ed. Harlow, UK: FT Prentice Hall.
Klein, K. J., and J. S. Sorra. 1996. The challenge of innovation implementation. The Academy of Management Review 21 (4): 1055-80.

Kotter, J. 1996. Leading change. Boston, MA: Harvard Business School Press.

Kotter, J. 2002. The heart of change. Boston, MA: Harvard Business School Press.

Manu, F. A., and V. Sriram. 1996. Innovation marketing strategy environment and performance. Journal of Business Research 35:79-91.

Meade, A. W., A. M. Watson, and C. M. Kroustalis. 2007. Assessing common methods bias in organizational research. Proceedings of the 22nd Annual Meeting of the Society for Industrial and Organizational Psychology, New York.

Nutt, P. 1986. Tactics of Implementation. The Academy of Management Journal 29 (2): 230-261.

Pellissier, R. 2011. The implementation of resilience engineering to enhance organizational innovation in a complex environment. International Journal of Business and Management 6 (1): 145-64.

Rogers, E. 1995. Diffusion of innovations. 4th edition. New York: Free Press.

Schumpeter, J. 1934. The theory of economic development. Cambridge: Harvard University Press.

Sharma, A., and N. Lacey. 2004. Linking product development outcomes to market valuation of the firm: The case of the U.S. pharmaceutical industry. Journal of Produce Innovation Management 21:297-308.

Siggelkow, N. 2002. Evolution toward fit. Administrative Science Quarterly 47 (1): 125-59.

Siguaw, J., P. Simpson, and C. Enz. 2006. Conceptualizing innovation orientation: A framework for study and integration of innovation research. Journal of Product Innovation Management 23:556-74.

Simpson, P., J. Siguaw, and C. Enz. 2006. Innovation orientation outcomes: The good and the bad. Journal of Business Research 59:1133-41.

Vargo, S., and R. Lusch. 2004. Evolving to a new dominant logic for marketing. Journal of Marketing 68 (January): 1-17.

Verma, R., C. Anderson, M. Dixon, C. Enz, G. Thompson, and L. Victorino. 2008. Key elements in service innovation: Insights for the hospitality industry. Cornell University Roundtable Proceedings, no. 1 (November). Ithaca, NY: Center for Hospitality Research Report, Cornell University.

Vila, M., C. Enz, and G. Costa. 2012. Innovative practices in the Spanish hotel industry. Cornell Hospitality Quarterly 51 (1): 75-85.

Weissenberger-Eibl, M., and D. J. Koch. 2007. Importance of industrial services and service innovations. Journal of Management and Organization 13 (2): 88-101.

Zirger, B., and M. Maidique. 1990. A Model of New Product Development: An Empirical Test. Management Science, 36 (7): $867-882$.

\section{Bio}

Cathy A. Enz, PhD, is the Lewis G. Schaeniman Jr. Professor of Innovation and Dynamic Management at the Cornell University School of Hotel Administration (cae4@cornell.edu). 